$\xi=-$ 圆

\title{
Stability Enhancement of STATCOM using Flower Pollination Algorithm
}

\author{
Srikanth Velpula ${ }^{1}$, Thirumalaivasan $\mathbf{R}^{1^{*}}$, Janaki $\mathbf{M}^{1}$ \\ ${ }^{1}$ School of Electrical Engineering, Vellore Institute of Technology, Vellore-632014, Tamilnadu, India. \\ *Corresponding author E-mail: thirumalai22@gmail.com
}

\begin{abstract}
The Static Synchronous Compensator (STATCOM) is a Voltage Source Converter (VSC) based shunt connected FACTS device. The key roles of STATCOM are to control the voltage at midpoint of transmission line, enhance power transfer capability and control reactive power at load end. However, the performance of STATCOM depends upon the parameters of the controller. In this paper, we present the tuning of Type- 1 controller parameters for STATCOM based on a systematic method using Flower Pollination Algorithm (FPA). The margins for the Type- 1 controller parameters are estimated from the movement of eigenvalues for the variation in controller parameters during inductive and capacitive modes of STATCOM. The performance of the STATCOM with FPA optimized Type-1 controller parameters is evaluated by transient simulation. The eigenvalue analysis and transient simulation are done based on D-Q model of STATCOM. It is noticed that, the response of STATCOM follows the step change in reactive current reference with least error.
\end{abstract}

Keywords: FACTS; Flower Pollination Algorithm (FPA); Static Synchronous Compensator (STATCOM); Voltage Source Converter (VSC).

\section{Introduction}

The Flexible AC Transmission Systems Controllers facilitate the fast and reliable control of the power system. The integration of FACTS controllers can alleviate the problem of under loading of transmission lines and improve system stability. The VSC based STATCOM is a shunt connected FACTS device which can supply a controlled reactive power to regulate the bus voltage where it is connected. The reactive power supply of STATCOM is regulated through controlling the output voltage of converter. The active power control of STATCOM is very small as the voltage on DC side is held by the capacitor. However, the use of energy storage across the DC capacitor enables the active power control capability of STATCOM. The noteworthy fact that the performance of the STATCOM and thereby the power system completely depends on the parameters of controller [1], [2].

In [3], a PI controller based STATCOM with varying DC capacitor voltage is presented to reduce the harmonics in current and voltage by fixing a modulation index. In [4], it is reported that Particle Swarm Optimization (PSO) based self tuning PI controller performs fast calculation of gains under varying load conditions. The tuning of PI controller parameters of STATCOM using Back Propagation Algorithm (BPA) and improvement in low convergence speed of BPA using the Bats Echolocation Algorithm are presented in [5]. In comparison to fixed gain and PSO based self tuned PI controller, the BPA based PI controller shows effective dynamic response of the STATCOM. The reactive current control of STATCOM using Fuzzy Logic PI controller eliminates the oscillatory instability in comparison to PI control [6]. The tuning of STATCOM controller gains using Artificial Neural Network (ANN) is presented in [7]-[10], which report that, the use of Fuzzy Logic improves the controller performance under various system conditions and consequently reduce the size of STATCOM. In
[11] - [12], the application of Genetic Algorithm (GA) to tune the controller parameters ensures D-stable of eigenvalues and the results show an excellent transient response of STATCOM under the considered range of operation and system conditions.

A biologically inspired meta-heuristic optimization technique called Flower Pollination Algorithm (FPA) was proposed by X-S. Yang in, 2012 [13], [14]. The inspiration for this algorithm is from the process of flower pollination in the plants. This is a very simple algorithm with only two operators, and a few of the parameters needs to set. The FPA is especially applied to many different disciplines in engineering, such as economic load dispatch problems [15], neural network training [16], machining process planning [17], and controller design [18].

In this paper, FPA is adopted to tune the controller parameters of STATCOM. A 24-pulse voltage source converter (VSC) and Type-1 controller are considered for STATCOM configuration [11], [19]. The Type-1 controller modulates the magnitude and phase angle of the converter output voltage relative to the supply voltage [1]. The performance of the STATCOM with FPA optimized controller parameters is evaluated through eigenvalue analysis and transient simulation. The results show the better transient performance and the system is stable under various operating conditions of STATCOM.

The structure of the paper as follows: Modeling of the STATCOM is described in Section 2. The design of current controller and application of FPA to optimize the controller parameters is reported in Section 3. The Section 4 presents results and discussions followed by conclusions in Section 5 .

\section{STATCOM Model}

The functional block diagram of STATCOM is shown in Fig.1. The coupling transformer having resistance $\left(\mathrm{R}_{\mathrm{s}}\right)$ and reactance 
$\left(\mathrm{X}_{\mathrm{s}}\right)$ is connected between the STATCOM and bus (with voltage $\mathrm{V}_{\mathrm{s}}$ ) to provide the isolation.

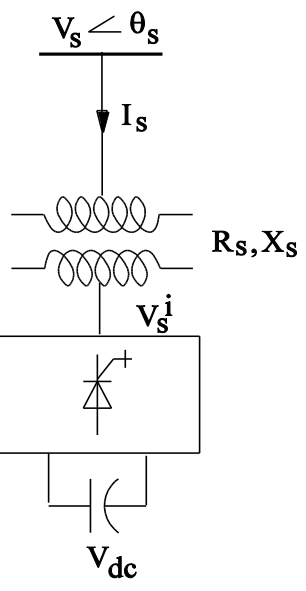

(a) Schematic

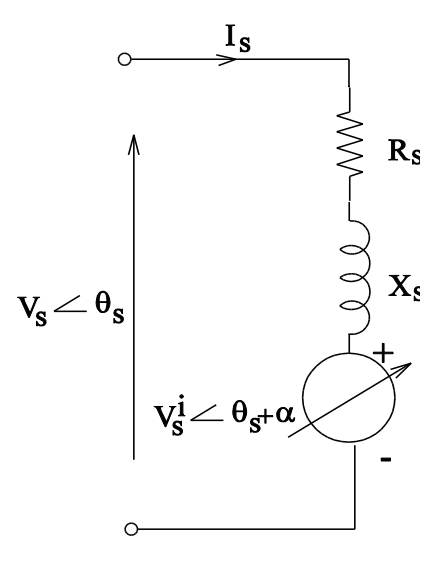

(b) Equivalent Circuit
Fig. 1: STATCOM configuration.

The converter of STATCOM is usually a multilevel or multi-pulse configuration. In a three-level converter with fundamental switching frequency, the magnitude of converter output voltage can be controlled by modulating the dead angle $\beta$ [20], [21]. Also, the three-level configuration of converter minimizes the harmonic distortion on the ac side [2], [19], [21] and [22].

In this paper, the phase angle and magnitude of the STATCOM converter output voltage are modulated using the Type- 1 controller. The transient performance is validated through D-Q model of STATCOM. In the modelling of STATCOM, the realization of three level is not considered.

\subsection{Mathematical Model of STATCOM in D-Q Refer- ence Frame}

The transformation of three-phase variables into D-Q frame is done with the Kron's transformation [23]. The output voltage of converter in D-Q reference frame is represented as:

$$
\begin{aligned}
& \mathrm{V}_{\mathrm{s}}^{\mathrm{i}}=\sqrt{\mathrm{V}_{\mathrm{sD}}^{\mathrm{i}}+\mathrm{V}_{\mathrm{sQ}}^{\mathrm{i}}{ }^{2}} \\
& \mathrm{~V}_{\mathrm{sD}}^{\mathrm{i}}=\mathrm{k}_{\mathrm{m}} \mathrm{V}_{\mathrm{dc}} \sin \left(\theta_{\mathrm{s}}+\alpha\right) \\
& \mathrm{V}_{\mathrm{sQ}}^{\mathrm{i}}=\mathrm{k}_{\mathrm{m}} \mathrm{V}_{\mathrm{dc}} \cos \left(\theta_{\mathrm{s}}+\alpha\right)
\end{aligned}
$$

The STATCOM equations in D-Q variables are described as:

$$
\begin{aligned}
& \frac{\mathrm{dI}_{\mathrm{sD}}}{\mathrm{dt}}=-\frac{\mathrm{R}_{\mathrm{s}} \omega_{\mathrm{B}}}{\mathrm{X}_{\mathrm{s}}} \mathrm{I}_{\mathrm{sD}}-\omega_{0} \mathrm{I}_{\mathrm{sQ}}+\frac{\omega_{\mathrm{B}}}{\mathrm{X}_{\mathrm{s}}}\left[\mathrm{V}_{\mathrm{sD}}-\mathrm{V}_{\mathrm{sD}}^{\mathrm{i}}\right]
\end{aligned}
$$

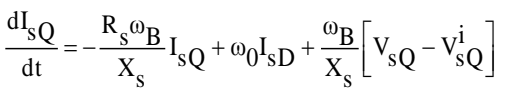

$$
\begin{aligned}
& \frac{d V_{d c}}{d t}=-\frac{{ }^{\omega} B}{b_{c}} I_{d c}+\frac{{ }^{\omega} B}{b_{c} R_{p}} V_{d c}
\end{aligned}
$$

Where $I_{d c}=-k_{m}\left[\sin \left(\theta_{s}+\alpha\right) I_{s D}+\cos \left(\theta_{s}+\alpha\right) I_{s Q}\right], I_{s D}$ and $I_{s Q}$ are the D$\mathrm{Q}$ variables of the STATCOM current, $\theta_{\mathrm{s}}$ is the phase angle of bus voltage, and $\alpha$ is the phase angle difference between fundamental component of the converter output voltage and STATCOM bus voltage $\mathrm{V}_{\mathrm{s}}$.

Here, $\mathrm{k}_{\mathrm{m}}$ is the modulation index of a three-level converter which is a function of dead angle $\beta$ and given by $\mathrm{k}_{\mathrm{m}}=\mathrm{k}^{1} \cos \beta$, where $\mathrm{k}^{1}=$ $\mathrm{k} \rho . \mathrm{k}=4 \sqrt{6} / \pi$ for a 24 -pulse converter and $\rho$ is transformation ratio of the STATCOM interfacing transformer.

\subsection{STATCOM Current Control}

The block diagram of Type- 1 controller for controlling the currents of STATCOM is shown in Fig.2. In Type-1 controller, the phase angle $\alpha$ and dead angle $\beta$ modulate the STATCOM currents. The phase angle $\alpha$ controls the real current of STATCOM. It is noted that, the conduction period of the converter depends on the dead angle $\beta$. Hence, by modulating dead angle $\beta$, the magnitude of converter output voltage is controlled, thereby controlling reactive current. While modulating the dead angle $\beta$, the DC voltage is held constant. In this work, the STATCOM reactive current is held constant to the value corresponding to the magnitude of the bus voltage.

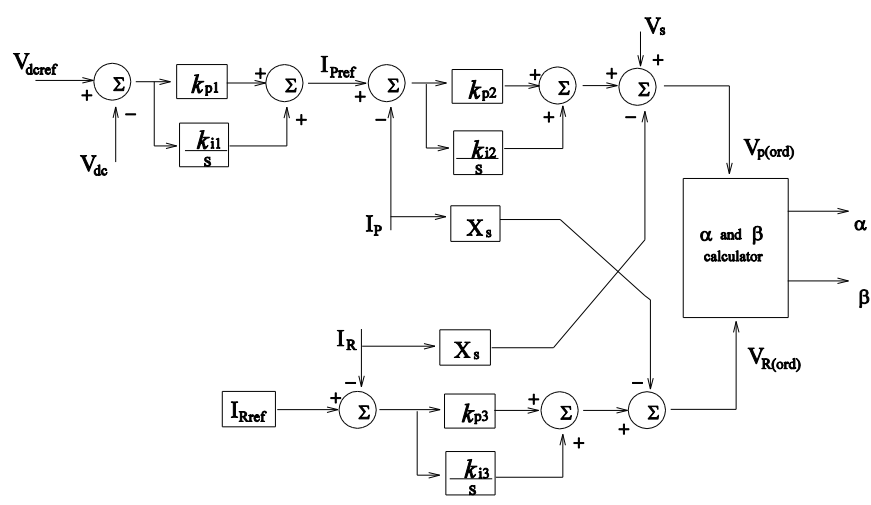

Fig. 2: Type-1 Controller.

The real and reactive current components of STATCOM in D-Q variables are represented as:

$$
\begin{aligned}
& \mathrm{I}_{\mathrm{P}}=\mathrm{I}_{\mathrm{sD}} \sin \left(\theta_{\mathrm{s}}\right)+\mathrm{I}_{\mathrm{sQ}} \cos \left(\theta_{\mathrm{s}}\right) \\
& \mathrm{I}_{\mathrm{R}}=-\mathrm{I}_{\mathrm{sD}} \cos \left(\theta_{\mathrm{s}}\right)+\mathrm{I}_{\mathrm{sQ}} \sin \left(\theta_{\mathrm{s}}\right)
\end{aligned}
$$

while the $\alpha, \beta$ are obtained from the equations:

$$
\begin{aligned}
& \alpha=\tan ^{-1}\left[\frac{\mathrm{V}_{\mathrm{R}(\text { ord })}}{\mathrm{V}_{\mathrm{P}(\text { ord })}}\right] \\
& \beta=\cos ^{-1}\left[\frac{\sqrt{\mathrm{V}_{\mathrm{R}(\text { ord })}+\mathrm{V}_{\mathrm{P}(\text { ord })}}}{\mathrm{k}^{1} \mathrm{~V}_{\mathrm{dc}}}\right]
\end{aligned}
$$

The $I_{P}$ and $I_{R}$ values are positive if the STATCOM absorbs real and reactive power.

\section{Design of Current Controller}

This section presents the design of current controller for STATCOM. To simplify the controller design procedure, the voltage of the STATCOM at the bus is assumed constant (the dynamics of the network are not considered).

\subsection{Trajectories of Eigenvalues}

The locus of eigenvalues are plotted with the variation in controller parameters for the range of ' 0 ' to ' 20 ' for the reactive current Reference of $-1,-0.5,0.5$ and 1 as shown in Fig.3. In Fig.3, the locus of eigenvalues are shown upto the range of ' -200 ' on real axis, for the range beyond the '-200' the eigenvalues are far away from the imaginary axis and considered to be stable. 

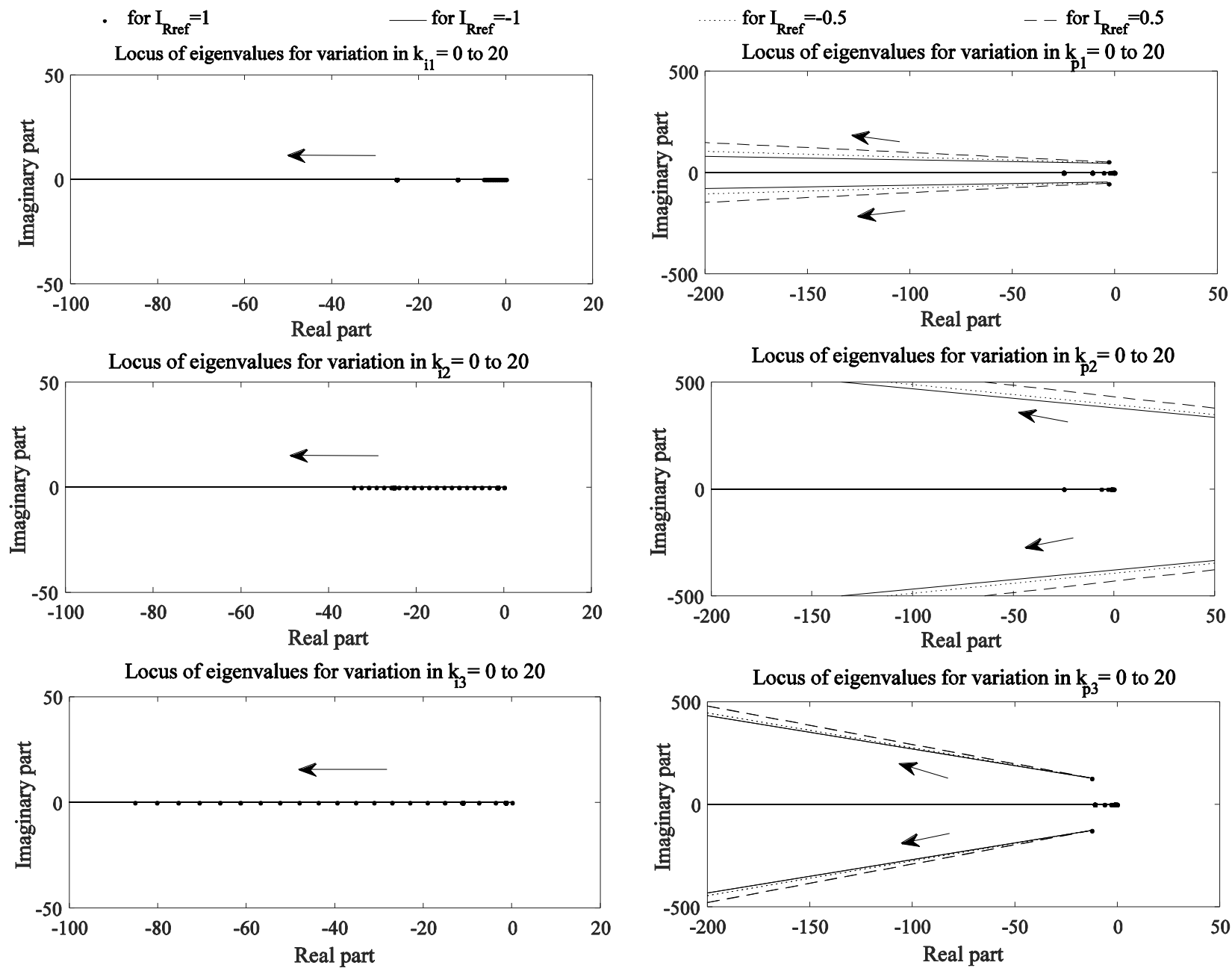

Fig. 3: Locus of the eigenvalues with the variation in control parameters for capacitive and inductive modes of STATCOM.

The trajectories of eigenvalues for the variation in controller parameters are shown in Fig.3. We can observe that for the low value of proportional controller gains, the location of eigenvalues are close to the imaginary axis with low damping, whereas unstable for low values of proportional gain of real current controller $\left(\mathrm{k}_{\mathrm{p} 2}\right)$. In general, the damping of the eigenvalues increases with increase in the gain of controller parameters. We tune the gains of controller to enhance the transient performance of STATCOM while maintaining the stability of STATCOM. Hence, from the trajectories of eigenvalues and the realistic values of controller parameters, we choose the upper and lower boundaries for controller parameters. The Flower Pollination Algorithm is used to find the optimal controller parameters for the stable operation of STATCOM under capacitive and inductive mode of operation.

\subsection{Application of Flower Pollination Algorithm (FPA) For Controller Parameter Optimization}

\subsubsection{Introduction to FPA}

The Flower Pollination Algorithm (FPA) is a population based meta-heuristic optimization technique, inspired by the flower pollination of plants. This optimization procedure imitates the flower pollination. The natural phenomenon of pollination plays an important role for the reproduction of flowering plants. The basic advantage of FPA is that the pollinators can travel for a long distances to enhance the algorithm to avoid local landscape and explores a larger search space. Also, the flower consistency of the algorithm promises that the flowers are chosen from the similar species which guarantees the fast convergence [13], [14] and [24].
The flexibility of the FPA in comparison to other algorithms is simple and can be applicable to single as well as multi objective functions. Concern to biological point of view, the ultimate objective of the flower pollination is the surviving of best fittest and optimal reproduction of plant species. With regard to the optimizing process in plants species, the FPA has four rules and summarized as [13], [14] and [24]:

Rule-1: Biotic and cross-pollination are considered as global pollination process. The pollinators which are carrying pollens obey the Lévy flights.

Rule-2: Self or Abiotic-pollination is treated to be a local pollination.

Rule-3: The pollinator constancy is regarded as the reproduction probability, which is proportional to the similarity of the two flowers involved.

Rule-4: The switching between the local and global pollination is controlled by the probability p $\varepsilon$ [0 1]

\subsubsection{Formulation of Objective Function}

The damping ratio $\zeta$ of around $10 \%$ to $20 \%$ is considered as acceptable to damp the oscillations. In most of the utilities, the allowable damping ratio is $10 \%$, which is considered to be the minimum requirement. As well as, real part of the eigenvalue is confined to be below a specific boundary, say $\alpha$, which ensures the less decay rate $\alpha$. The boundary of real part $\alpha=-0.5$ is considered as sufficient to ensure the settling time which should be an acceptable value. To ensure the acceptable controlled system, the closed loop pole location must simultaneously meet either condi- 
tions with an acceptable response for small disturbance under specified range of operating conditions.

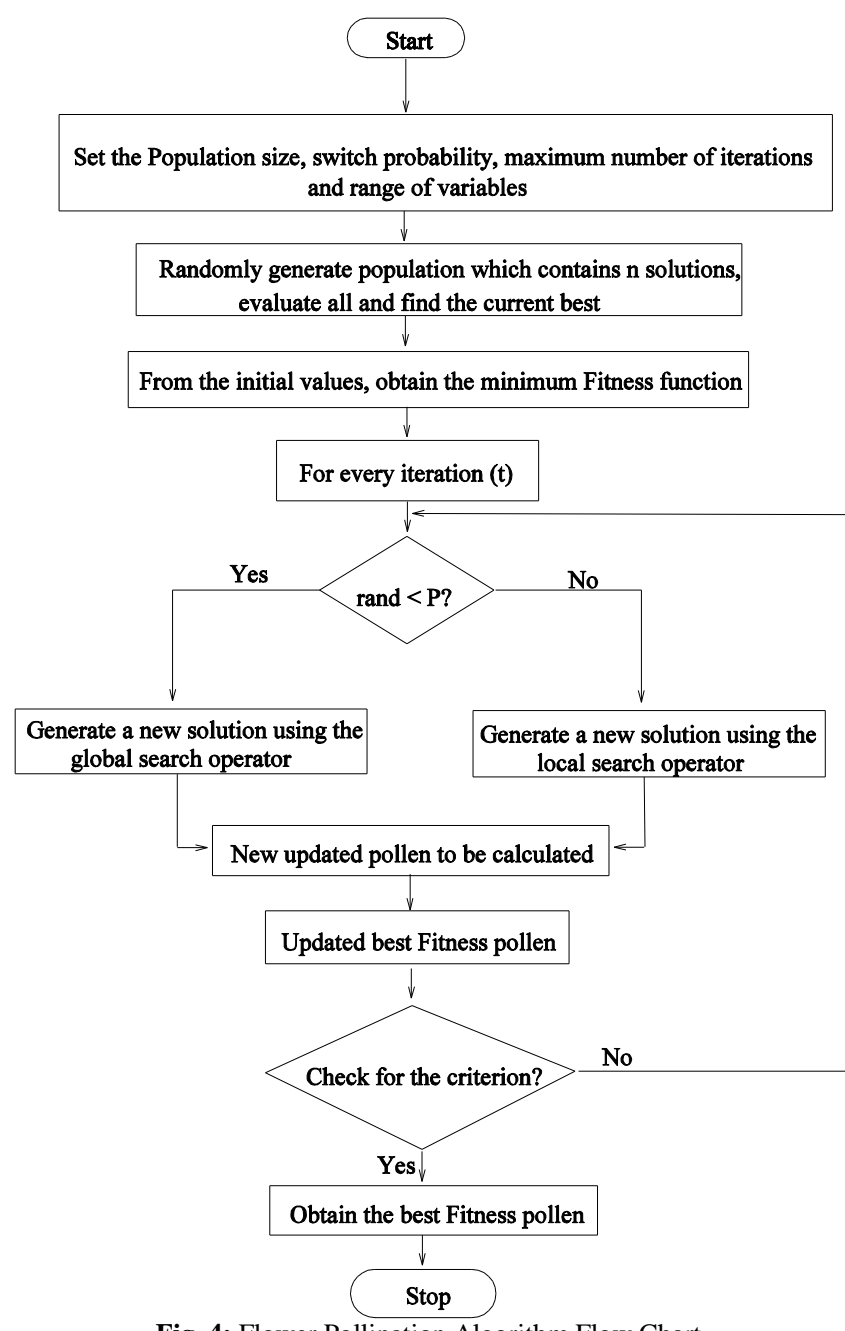

Fig. 4: Flower Pollination Algorithm Flow Chart.

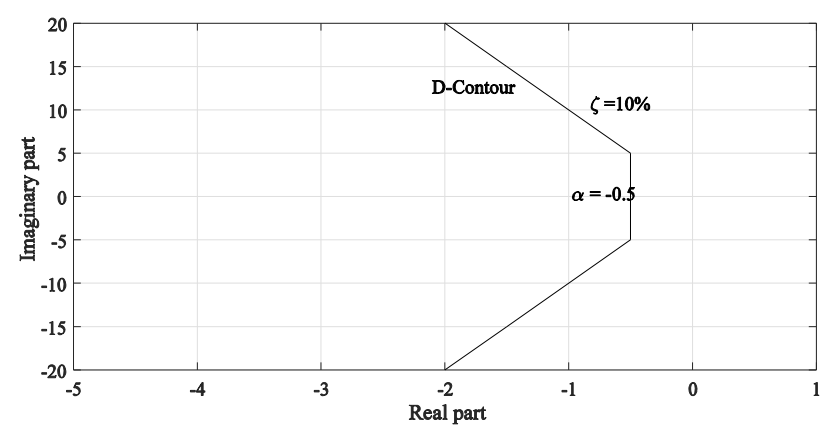

Fig. 5: D-contour specified with $\zeta=10 \%$ and $\alpha=-0.5$.

When the location of all the eigenvalues are in the left side of the contour shown in Fig.5, the conditions on $\zeta$ and $\alpha$ are met and also guarantees a well damped response for small disturbance. The contour which is shown in Fig.5 is referred as the D-contour [2], [25].

According to this, a system is said to be D-stable, if all the eigenvalues lie to the left side of the $\mathrm{D}$-contour. The controller which ensures the D-stability of a closed loop system under a wide range of system operating conditions is said to be a 'robust' controller. Therefore a system said to be 'robust', if, for all the range of system operating conditions the eigenvalues lie on left side of the Dcontour.

The D-contour shown in Fig.5 can be mathematically described as:
$\mathrm{f}(\mathrm{z})=\operatorname{Re}(\mathrm{z})-\min [-\operatorname{Im}(\mathrm{z}), \alpha]=0$

Where $\mathrm{z} \varepsilon \mathrm{C}$, represents a point of the D-contour on the complex plane $\mathrm{C}$.

$\mathrm{J}$ is defined as:

$J=\max _{i}\left[\operatorname{Re}\left(\lambda_{i}\right)-\max _{i=1,2,3 \ldots n}\left(-\zeta\left|\operatorname{Im}\left(\lambda_{i}\right)\right|, \alpha\right]\right.$

Where ' $\lambda_{i}$ ' is the $i^{\text {th }}$ eigenvalue of the system, ' $n$ ' is the number of eigenvalues.

The negative value of all the elements of ' $\mathrm{J}$ ' indicate that all the eigenvalues lie on left side of the D-contour, the system is said to be $\mathrm{D}$-stable. Conversely, the eigenvalues to the right side of the $\mathrm{D}$ contour result in one or more elements of ' $\mathrm{J}$ ' to the positive value. From the facts discussed above, the objective function ' $E$ ' is defined as:

Sum Squared Error $(\mathrm{E})=\sum_{p=1,2, \ldots m} e^{2}$

Where $e=\mathrm{I}_{\text {Rref }}-\mathrm{I}_{\mathrm{R}}$, and $\mathrm{m}=$ size of $\mathrm{I}_{\text {Rref }}$ array with transient simulation carried out for $1.5 \mathrm{sec}, \mathrm{I}_{\text {Rref }}$ is the reactive current reference and $I_{R}$ is the reactive current of STATCOM.

For the satisfactory operation of STATCOM, the difference between reactive current reference $I_{R r e f}$ and reactive current $I_{R}$ (i.e., error 'e') should be minimum. Hence, the problem of optimization can be written as:

Minimize E

subjected to $\mathrm{J} \leq 0$

Also, the boundaries for the controller parameters are described as:

$k_{p 1 \min } \leq k_{p 1} \leq k_{\text {pImax }}$

$k_{p 2 \min } \leq k_{p 2} \leq k_{p 2 \max }$

$k_{p 3 \min } \leq k_{p 3} \leq k_{p 3 \max }$

$$
\begin{aligned}
& k_{i l \min } \leq k_{i 1} \leq k_{i 1 \max } \\
& k_{i 2 \min } \leq k_{i 2} \leq k_{i 2 \max } \\
& k_{i 3 \min } \leq k_{i 3} \leq k_{i 3 \max }
\end{aligned}
$$

\section{Results and Discussions}

In the FPA optimization process, the minimum value of the objective function is found for various number of iterations and population sizes.

The best minimum value of objective function versus number of iterations with different population sizes are plotted in Fig.6. The best minimum value of objective function occurs at less number of iterations for the increase in population as shown in Fig.6. At this point of minimal objective function the controller parameters are considered to be optimal values.

The optimized parameters obtained by FPA are:

$k_{p l}=0.71585, k_{p 2}=0.2518, \quad k_{p 3}=0.21367$,

$k_{i l}=5.1226, \quad k_{i 2}=0.14777, \quad k_{i 3}=4.5134$.

The location of eigenvalues in complex plane for the entire range of capacitive and inductive modes of STATCOM with optimal Type-1 controller parameters is plotted in Fig.7. The corresponding eigenvalues for the capacitive and inductive mode of operation of the STATCOM are shown in Table 1.

In Fig.7, the eigenvalues are lying on left side of the D-contour with the optimal controller parameters. Thus, the optimization of controller parameters using FPA shows the D-stable system under various operating conditions considered.

The performance of the STATCOM with FPA optimized parameters for Type- 1 is determined by transient simulation and eigenvalue analysis. In transient simulation, the step change in the reference value of reactive current reference is applied from $0.5 \mathrm{sec}$ to 1 sec. During the step change, the STATCOM operation is changed from maximum capacitive to maximum inductive and vice versa. The step response of STATCOM with optimized controller para meters is plotted in Fig.8, which shows the smooth transition between capacitive and inductive mode of STATCOM. 

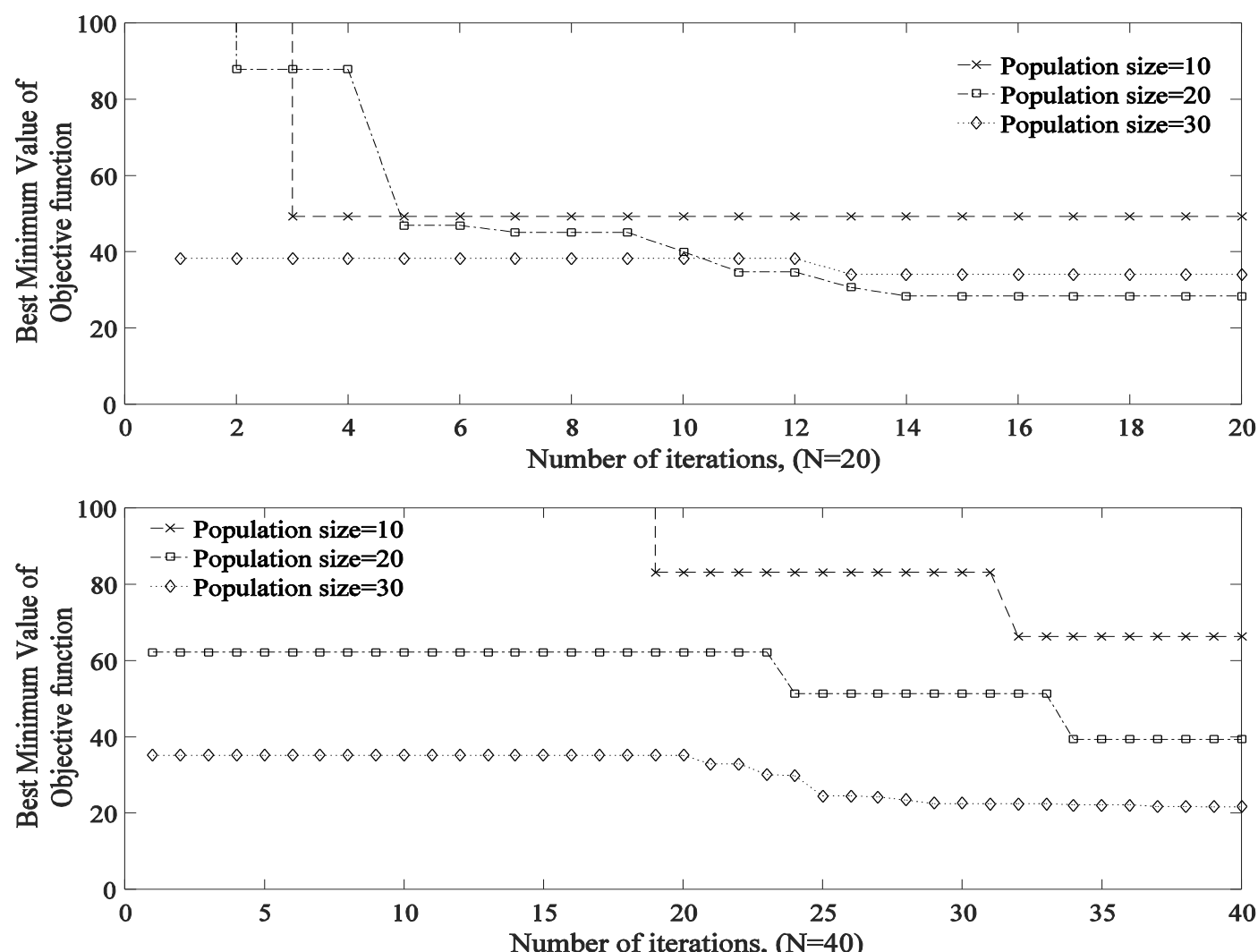

Fig. 6: Best Minimum Value of Objective function versus Number of iterations with different Population sizes.

Table1: Eigenvalues with optimal controller parameters based on FPA

\begin{tabular}{|c|c|}
\hline $\begin{array}{c}\text { Capacitive Region } \\
\mathrm{i}_{\mathrm{R}}=-1\end{array}$ & $\begin{array}{c}\text { Inductive Region } \\
\mathrm{i}_{\mathrm{R}}=1\end{array}$ \\
\hline$-328.68 \pm \mathrm{j} 263.28$ & $-328.63 \pm \mathrm{j} 362.85$ \\
\hline-541.18 & -541.18 \\
\hline-20.96 & -20.96 \\
\hline-7.1212 & -7.1304 \\
\hline-0.58691 & -0.58691 \\
\hline
\end{tabular}
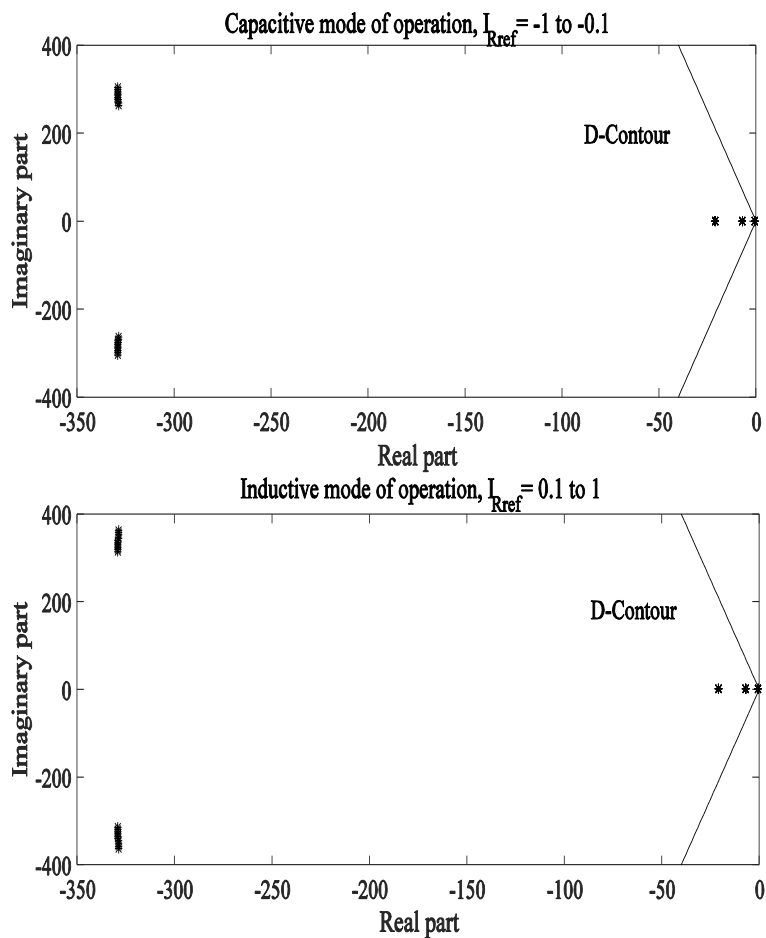

Fig. 7: Locus of eigenvalues of STATCOM with optimal controller parameters.

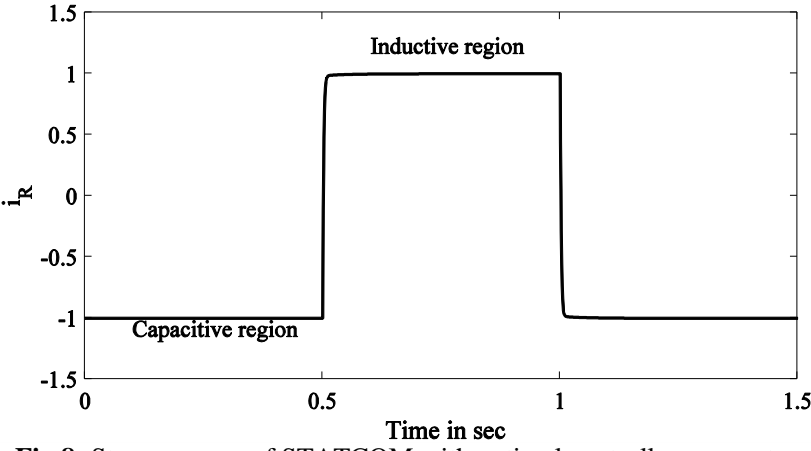

Fig.8: Step response of STATCOM with optimal controller parameters.

\section{Conclusion}

In this paper, the optimization of controller parameters for STATCOM current control using Flower Pollination Algorithm is presented. The range of controller parameters is selected from the eigenvalue analysis. The results show that the eigenvalues of STATCOM with optimized controller parameters are D-Stable for the capacitive and inductive mode of operation. The step response of STATCOM with optimized controller parameters is tested and it is observed that the STATCOM shows an excellent transient response.

\section{References}

[1] Hingorani N G \& Gyugyi L (2000), Understanding FACTS, IEEE Press, New York, pp. 135-205.

[2] Padiyar K R (2007), FACTS Controllers in Power Transmission and Distribution, New age International (P) Ltd, India, pp.173-213.

[3] B. S. Chen \& Y. Y. Hsu (2008), A minimal harmonic controller for a STATCOM," IEEE Trans. Ind. Electron., vol. 55, no. 2, pp. 655664. 
[4] C. H. Liu \& Y. Y. Hsu (2010), Design of a self-tuning PI controller for a STATCOM using particle swarm optimization, IEEE Trans. Ind.Electron., vol. 57, no. 2, pp. 702-715.

[5] Kumaravel G \& C. Kumar (2012), Design of self tuning PI controller for STATCOM using Bats Echolocation Algorithm based Neural controller, Int. Conf. on Advances in Engineering, Science and Management (ICAESM), IEEE, pp. 276-281.

[6] K. R. Padiyar \& A. M. Kulkarni (1997), Design of reactive current and voltage controller of static condenser, Int. J. Electr. Power Energy Syst., vol. 19, no. 6, pp. 397-410.

[7] C. T. Chang \& Y. Y. Hsu (2003), Design of an ANN tuned adaptive UPFC supplementary damping controller for power system dynamic performance enhancement, Electr. Power Syst. Res., vol. 66, no. 3, pp. 259-265.

[8] S. Mohagheghi, Y. del Valle, G. K. Venayagamoorthy \& R. G. Harley (2007), A proportional-integral type adaptive critic designbased neuro controller for a static compensator in a multi machine power system, IEEE Trans. Ind. Electron., vol. 54, no. 1, pp. 86-96.

[9] S. Mohagheghi, R. G. Harley \& G. K. Venayagamoorthy (2005), An adaptive Mamdani fuzzy logic based controller for STATCOM in a multi machine power system, in Proc. ISAP, pp. 228-233.

[10] S. Mohagheghi, G. K. Venayagamoorthy \& R. G. Harley (2008), Fully evolvable optimal neuro fuzzy controller using adaptive critic designs, IEEE Trans. Fuzzy Syst., vol. 16, no. 6, pp. 14501461.

[11] M. Janaki, R. Thirumalaivasan \& N. Prabhu (2011), Design of robust current controller using GA for three level 24-pulse VSC based STATCOM, J. Power Electron., vol. 11, no. 3, pp. 375-380.

[12] M. Janaki, R. Thirumalaivasan \& N. Prabhu (2011), Design of robust current controller for two-level 12-pulse VSC-based STATCOM," Adv. Power Electron., pp. 1-7.

[13] X.-S. Yang (2012), Flower pollination algorithm for global optimization, in Unconventional Computation and Natural Computation, ed: Springer, pp. 240-249.

[14] Yang, Xin-She, Mehmet Karamanoglu \& Xingshi He (2014) Flower pollination algorithm: a novel approach for multi objective optimization, Engineering Optimization, vol. 46, pp. 1222-1237.

[15] Dubey, Hari Mohan, Manjaree Pandit \& B. K. Panigrahi (2015) Hybrid flower pollination algorithm with time-varying fuzzy selection mechanism for wind integrated multi-objective dynamic economic dispatch, Renewable Energy, vol. 83, pp. 188-202.

[16] Chiroma, Haruna, et al (2016), A new approach for forecasting OPEC petroleum consumption based on neural network train by using flower pollination algorithm, Applied Soft Computing, vol. 48, pp. 50-58.

[17] Xu, Shuhui, Yong Wang \& Fengyue Huang (2017), Optimization of multipass turning parameters through an improved flower pollination algorithm, The International Journal of Advanced Manufacturing Technology, vol. 89, pp. 503-514.

[18] Dash, Puja, Lalit Chandra Saikia \& Nidul Sinha (2016), Flower pollination algorithm optimized PI-PD cascade controller in automatic generation control of a multi-area power system, International Journal of Electrical Power and Energy Systems, vol. 82, pp. 19 28.

[19] K. R. Padiyar \& N. Prabhu (2006), Design and performance evaluation of subsynchronous damping controller with STATCOM, IEEE Trans. Power Del., vol. 21, no. 3, pp. 1398-1405.

[20] K. R. Padiyar \& V. S. Prakash (2003), Tuning and performance evaluation of damping controller for a STATCOM, Int. J. Electr. Power and Energy Syst., vol. 25, no. 2, pp. 155-166.

[21] K. R. Padiyar \& N. Prabhu (2003), Analysis of sub synchronous resonance with three level twelve-pulse VSC based SSSC, in Proc. IEEE TENCON-2003, vol. 1, pp. 76-80.

[22] N. Prabhu (2004), Analysis of SubSynchronous Resonance with Voltage Source Converter based FACTS and HVDC Controllers, Ph.D. dissertation, IISc Bangalore.

[23] K. R. Padiyar (2000), Power System Dynamics Stability and Control, Second Edition, B.S. Publications, Hyderabad, pp. 153-157.

[24] D. F. Alam, D. A. Yousri \& M. B. Eteiba (2015), Flower Pollination Algorithm based solar PV parameter estimation, Energy Convers. Manag., vol. 101, pp. 410-422.

[25] R. Singh (2004), A Novel Approach for Tuning of Power System Stabilizer Using Genetic Algorithm, M.Sc. dissertation, Indian Inst. of Sci., Bangalore, India. 